\title{
NUMERICAL INVESTIGATION FOR THE START CONTROL AND FINAL OBSERVATION PROBLEM IN MODEL OF AN I-BEAM DEFORMATION
}

N. A. Manakova ${ }^{1}$, manakovana@susu.ru,

K. V. Vasiuchkova ${ }^{1}$, vasiuchkovakv@susu.ru

${ }^{1}$ South Ural State University, Chelyabinsk, Russian Federation

The article considers the start control and the final observation of solutions to the Showalter - Sidorov problem for the mathematical model of an I-beam deformation. We construct the sufficient conditions for the existence of the start control and the final observation by weak generalized solutions of the considered model with the initial Showalter - Sidorov condition. Based on the theoretical results, we construct the algorithm of the numerical method to solve the problem of start control and final observation for the model of an I-beam deformation. The results of computational experiments are presented.

Keywords: Sobolev type equation; problem of start control and final observation; model of I-beam deformation; the Galerkin method; decomposition method.

\section{Introduction}

Let $\Omega \subset \mathbb{R}^{n}$ be a bounded domain with a boundary $\partial \Omega$ of class $C^{\infty}$. In the cylinder $\Omega \times \mathbb{R}_{+}$consider the generalized Hoff equation

$$
(-\lambda-\Delta) x_{t}+\alpha_{0} x+\alpha_{1} x^{3}+\alpha_{2} x^{5}+\ldots+\alpha_{k-1} x^{2 k-1}+\alpha_{k} x^{2 k+1}=y
$$

with the Dirichlet condition

$$
x(s, t)=0, \quad(s, t) \in \partial \Omega \times \mathbb{R}_{+}
$$

and the Showalter - Sidorov condition

$$
(\lambda+\Delta)(x(s, 0)-u(s))=0, \quad s \in \Omega .
$$

The equation (1) simulates an I-beam buckling dynamics. The function $x=x(s, t)$ shows the deviation of the beam from the equilibrium position. The parameter $\lambda \in \mathbb{R}$ characterizes a load, and the parameters $\alpha_{i} \in \mathbb{R}_{+}(i=0, \ldots, k)$ describe properties of the beam material, $y=y(s, t)$ is an external (side, in the case $n=1$ ) influence. The equation (1) was obtained by N. J. Hoff [1] for $n=1$. Many researches consider the Hoff equation (1) in various aspects. For example, the morphology of phase space for the equation (1) is investigated in [2], the Hoff equation on graphs is considered in [3, 4], the optimal control 
problem for this equation is investigated in [5], and also the Cauchy problem for the Hoff equation is considered on manifold in [6].

The equation (1) and the condition (2) are model of deformation of an I-beam under constant load. The initial-boundary problem (2), (3) for the equation (1) in the specially constructed functional Banach spaces is reduced to the Showalter - Sidorov problem

$$
L(x(0)-u)=0
$$

for the abstract semilinear equation

$$
L \dot{x}+M(x)=y, \quad \operatorname{ker} L \neq\{0\} .
$$

Our purpose is to investigate the start control and final observation

$$
J(x(T), u) \rightarrow \inf , \quad u \in \mathfrak{U}_{a d}
$$

by weak generalized solutions of the problem (4), (5). Here $J(x(T), u)$ is a specially constructed target functional; $u \in \mathfrak{U}_{a d}$, and $\mathfrak{U}_{a d}$ is a closed and convex set in the space of controls $\mathfrak{U}$. The problem of start control and final observation simulates the situation when the moment of result observation is separated in time from the start influence, i.e. control. The problem $(1)-(3)$, (6) describes process to find the initial curvature $u(s)$ of I-beam such that the I-beam takes the required form $x(s, T)$ under the constant load $\lambda$ during the time $T$. If the equation of state is nonlinear, then the finding the start control is difficult. One of the approaches to solve this problem is the decomposition method $[7,11]$. This method allows to linearize the initial equation and to transfer the phenomenon of nonlinearity to the functional. Therefore, the numerical scheme to find the approximate solution to the problem of start control and final observation is simplified.

Most of known physical processes are controllable. Different factors can influence on the control. The external influence on the process is very important. Therefore, the investigation of the control problems has the practical nature. In order to obtain the optimal control law, the mathematical, algorithmic and software tools are developed. For the first time, the linear problem of optimal control for the linear Sobolev type equation with the Cauchy condition was investigated by G. A. Sviridyuk and A. A. Efremov [8]. Further, these results are developed in $[5,9,10]$. The article [12] presents the sufficient conditions for the solvability of the problem of start control and final observation for an abstract quasilinear Sobolev-type equation in the weak generalized sense.

The paper is organized as follows. The first paragraph presents a reduction of the problem (1) - (3) to the abstract problem (4), (5). To this end, we construct the function spaces and show the basic properties of the operators, establish an existence of the weak generalized solution to the problem (1) - (3). Also, we study the problem of start control and final observation (1) - (3), (6) and present the sufficient conditions for the existence of solution to the considered problem. In order to study the question of existence and uniqueness of the weak generalized solution to the problem (1) - (3), we use the monotonicity method and the Galerkin method. Our results are similar to [13 - 15]. In the second paragraph we present the algorithm of numerical method to find the start control and final observation to the model of an I-beam deformation, based on the method of decomposition, the Ritz method and the penalty method. The results of computation experiments are given. 


\section{Analytical Study of the Problem of Start Control and Final Observation}

Let us consider the functional spaces $\mathfrak{N}=\stackrel{\circ}{W_{2}^{1}}(\Omega), \mathfrak{B}=L_{2 k+2}(\Omega), \mathcal{H}=L_{2}(\Omega)$, defined in the domain $\Omega$. Let $\mathfrak{B}^{*}, \mathfrak{N}^{*}$ be dual spaces to $\mathfrak{B}$ and $\mathfrak{N}$, relative to the scalar product $<\cdot, \cdot>$ in $\mathcal{H}$, respectively. According to the Sobolev theorem, if $k=1$ for $n=4$ or $k=1,2$ for $n=3$ or $k \in \mathbb{N}$ for $n=1,2$, there exist dense and continuous embeddings

$$
\mathfrak{N} \hookrightarrow \mathfrak{B} \hookrightarrow \mathcal{H} \hookrightarrow \mathfrak{B}^{*} \hookrightarrow \mathfrak{N}^{*}
$$

and the embedding $\mathfrak{N} \hookrightarrow \mathcal{H}$ is compact. Define operators

$$
\begin{gathered}
<L x, \zeta>=\int_{\Omega}(\nabla x \cdot \nabla \zeta-\lambda x \zeta) d s, \quad x, \zeta \in \mathfrak{N} ; \\
<M(x), \zeta>=\int_{\Omega}\left(\alpha_{0} x \zeta+\alpha_{1} x^{3} \zeta+\alpha_{2} x^{5} \zeta+\ldots+\alpha_{k-1} x^{2 k-1} \zeta+\alpha_{k} x^{2 k+1} \zeta\right) d s, \quad x, \zeta \in \mathfrak{B} .
\end{gathered}
$$

Let $\left\{\varphi_{k}\right\}$ be a sequence of eigenfunctions of the homogeneous Dirichlet problem for the operator $(-\Delta)$ in the domain $\Omega$ and $\left\{\lambda_{k}\right\}$ be the corresponding sequence of eigenvalues, numbered in non-decreasing order taking into account their multiplicity.

Definition 1. An operator $M: \mathfrak{B} \rightarrow \mathfrak{B}^{*}$ is called $p$-coercive, if $\exists C^{M}, C_{M}>0$, and $\exists p \geq 2$ such that $\langle M(x), x\rangle \geq C_{M}\|x\|^{p}$ and $\|M(x)\|_{*} \leq C^{M}\|x\|^{p-1}, \forall x \in \mathfrak{B}$.

Definition 2. Let $x, y$ be any elements from $\mathfrak{B}$. An operator $M: \mathfrak{B} \rightarrow \mathfrak{B}^{*}$ is called $s$-monotonous, if $M \in C^{r}\left(\mathfrak{B} ; \mathfrak{B}^{*}\right), r \geq 1$, and

$$
\left\langle M_{\zeta}^{\prime} x, x\right\rangle>0, \quad x, \zeta \neq 0 .
$$

Lemma 1. [4] (i) For all $\lambda \leq \lambda_{1}$ the operator $L \in \mathcal{L}\left(\mathfrak{N}, \mathfrak{N}^{*}\right)$ is self-adjoint, Fredholm and non-negative defined, and an orthonormal family $\left\{\varphi_{k}\right\}$ form basis in $\mathfrak{N}$.

(ii) For any $\alpha_{i} \in \mathbb{R}_{+}, i=0, . ., k$, the operator $M \in C^{\infty}\left(\mathfrak{B}, \mathfrak{B}^{*}\right)$ is s-monotonous and $(2 k+2)$-coercive.

Therefore, the problem (1) - (3) is reduced to the Showalter - Sidorov problem (4) for the semilinear equation (5).

Let us search for the approximate solutions to the problem (1) - (3) in the form

$$
x_{m}(s, t)=\sum_{i=1}^{m} a_{i}(t) \varphi_{i}(s), \quad m>\operatorname{dim} \operatorname{ker}(-\lambda-\Delta),
$$

where the coefficients $a_{i}=a_{i}(t), i=1, \ldots, m$, are determined by the system of equations

$$
\begin{array}{r}
\int_{\Omega}\left((-\lambda-\Delta) \frac{d x_{m}}{d t}+\alpha_{0} x_{m}+\alpha_{1} x_{m}^{3}+\alpha_{2} x_{m}^{5}+\ldots+\alpha_{k-1} x_{m}^{2 k-1}+\alpha_{k} x_{m}^{2 k+1}\right) \varphi_{i} d s= \\
=\int_{\Omega} y \varphi_{i} d s, \quad i=1, \ldots, m
\end{array}
$$


and the conditions

$$
\int_{\Omega}\left((-\lambda-\Delta)\left(x_{m}(s, 0)-u(s)\right)\right) \varphi_{i}(s) d s=0, \quad i=1, . ., m .
$$

Construct the set

$$
\operatorname{coim}(-\lambda-\Delta)=\{x \in \mathfrak{N}: \quad\langle x, \varphi>=0 \quad \forall \varphi \in \operatorname{ker} L \backslash\{0\}\}
$$

and consider the space

$$
\mathfrak{X}=\left\{x \mid x \in L_{\infty}(0, T ; \operatorname{coim}(-\lambda-\Delta)) \cap L_{2 k+2}\left(0, T ; L_{2 k+2}(\Omega)\right)\right\} .
$$

Definition 3. A vector-function $x \in \mathfrak{X}$ for $T \in \mathbb{R}_{+}$is called a weak generalized solution to the Showalter - Sidorov problem (1) - (3), if it satisfies

$$
\begin{gathered}
\int_{0}^{T}<L \frac{d x}{d t}+M(x), \zeta>\varphi(t) d t=\int_{0}^{T}<y, \zeta>\varphi(t) d t, \zeta \in \mathfrak{N}, \varphi \in L_{2}(0, T), \\
<L(x(0)-u), \zeta>=0 \text { for almost all } t \in(0, T) .
\end{gathered}
$$

Suppose that $T_{m} \in \mathbb{R}_{+}, T_{m}=T_{m}\left(x_{0}\right), \mathfrak{N}^{\mathfrak{m}}=\operatorname{span}\left\{\varphi_{1}, \varphi_{2}, \ldots, \varphi_{m}\right\}$.

Lemma 2. [17] For every $u \in \mathfrak{N}$ and $m>\operatorname{dim} \operatorname{ker} L$ there exists a unique solution $x_{m} \in$ $C^{1}\left(0, T ; \mathfrak{N}^{\mathfrak{m}}\right)$ to the problem $(9),(10)$.

Theorem 1. [17] Let $k=1$ for $n=4$ or $k=1,2$ for $n=3$ or $k \in \mathbb{N}$ for $n=1,2$ and $\lambda \leq \lambda_{1}, \alpha_{i} \in \mathbb{R}_{+}, i=0, . ., k, T \in \mathbb{R}_{+}$. Then for every $u \in \stackrel{\circ}{W_{2}^{1}(\Omega)}$ and $y \in L_{\frac{2 k+2}{2 k+1}}\left(0, T ; L_{\frac{2 k+2}{2 k+1}}(\Omega)\right)$ there exists a unique weak generalized solution $x \in \mathfrak{X}$ to the problem $(1)-(3)$.

Construct the space of controls $\mathfrak{U}=\mathfrak{N}$ and let $\mathfrak{U}_{a d} \subset \mathfrak{U}$ be non-empty, closed, convex set. Consider the problem of start control and final observation (1) - (3), (6), where the target functional is defined in the form:

$$
J(x(T), u)=\vartheta\left\|x(T)-x_{f}\right\|_{\mathfrak{B}}^{2 k+2}+(1-\vartheta)\|u\|_{\mathfrak{N}}^{2}, \quad \vartheta \in(0,1) .
$$

Here $x_{f}=x_{f}(s)$ is the desired state of the system. It is necessary to achieve this state with the minimal initial influence during the time $t=T$.

Definition 4. A pair $(\hat{x}(T), \hat{u}) \in \mathfrak{N} \times \mathfrak{U}_{a d}$ is called a solution to the problem $(1)-(3),(6)$, if

$$
J(\hat{x}(T), \hat{u})=\inf _{(x(T), u)} J(x(T), u),
$$

where the pairs $(\hat{x}, \hat{u}) \in \mathfrak{X} \times \mathfrak{U}_{a d}$ satisfy to the problem $(1)-(3)$. The vector-function $\hat{u}$ is said to be the start control of the problem $(1)-(3),(6)$. 
Remark 1. A pair $(x(T), u) \in \mathfrak{N} \times \mathfrak{U}_{a d}$ is called an admissible element of the problem $(1)-(3),(6)$, where $(x, u) \in \mathfrak{X} \times \mathfrak{U}_{a d}$ is a weak generalized solution to the problem (1) - (3) such that

$$
J(x(T), u)<+\infty .
$$

According to the Theorem 1 , if the set $\mathfrak{U}_{a d} \neq \emptyset$, then for every $u \in \mathfrak{U}_{a d}$ their exists a unique solution $x=x(y, u)$ to the problem $(1)-(3)$. Hence, the set of admissible elements of the problem is nonempty.

Theorem 2. Let $k=1$ for $n=4$ or $k=1,2$ for $n=3$ or $k \in \mathbb{N}$ for $n=1,2$ and $\lambda \leq \lambda_{1}$, $\alpha_{i} \in \mathbb{R}_{+}, i=0, . ., k, T \in \mathbb{R}_{+}$. Then for every $y \in L_{\frac{2 k+2}{2 k+1}}\left(0, T ; L_{\frac{2 k+2}{2 k+1}}(\Omega)\right)$ their exists the solution $(\hat{x}(T), \hat{u})$ to the problem $(1)-(3),(6)$.

Proof. The Theorem 1 provides that the operator $\left(L \frac{d}{d t}+M\right): \mathfrak{X} \rightarrow \mathfrak{U}$ is homeomorphism. Then the functional (11) can be represented in the form

$$
J(x(T), u)=J(u)=\vartheta\left\|x(u)-x_{f}\right\|_{\mathfrak{B}}^{2 k+2}+(1-\vartheta)\|u\|_{\mathfrak{N}}^{2}, \vartheta \in(0,1) .
$$

Let $\left\{u_{m}\right\} \subset \mathfrak{U}_{a d}$ be a sequence such that

$$
\lim _{m \rightarrow \infty} J\left(u_{m}\right)=\inf _{u \in \mathfrak{U}_{a d}} J(u)
$$

then (12) provides that

$$
\left\|u_{m}\right\|_{\mathfrak{N}} \leq \text { const, } \forall m \in \mathbb{N} .
$$

From (13) (move to a subsequence if necessary) we choose a weakly converging sequence $u_{m} \rightarrow \hat{u}$ in $\mathfrak{N}$. According to the Mazur theorem, the point $\hat{u} \in \mathfrak{U}_{a d}$. Let $x_{m}=x\left(u_{m}\right)$ be a weakly generalized solution to the problem

$$
\begin{gathered}
\frac{d}{d t} L x_{m}+M\left(x_{m}\right)=y, \\
L\left(x_{m}(0)-u_{m}\right)=0 .
\end{gathered}
$$

Introduce the norm $|x|^{2}=\left\langle L x, x>\right.$ in coim $L$, multiply the equation (14) by $x_{m}(t)$ and integrate on $(0, t)$ :

$$
\begin{gathered}
\left\langle L x_{m}(t), x_{m}(t)\right\rangle+2 \int_{0}^{t}\left\langle M\left(x_{m}\right), x_{m}\right\rangle d \tau=2 \int_{0}^{t}\left\langle y(\tau), x_{m}(\tau)\right\rangle d \tau+\left\langle L x_{m}(0), x_{m}(0)\right\rangle \leq \\
\leq \frac{(2 k+1) \varepsilon^{\frac{2 k+2}{2 k+1}}}{2 k+2}\|y\|_{\frac{2 k+2}{2 k+1}}^{\frac{2 k+2}{2 k+1}}\left(0, T ; \mathfrak{B}^{*}\right) \\
\quad \frac{1}{(2 k+2) \varepsilon^{2 k+2}}\left\|x_{m}\right\|_{L_{2 k+2}(0, T ; \mathfrak{B})}^{2 k+2}+\left|u_{m}\right|^{2} .
\end{gathered}
$$

The operator $M$ is $(2 k+2)$-coercivity. Then, for every arbitrary constant $\varepsilon$ such that $2 C_{M}-\frac{1}{(2 k+2) \varepsilon^{2 k+2}}>0$ we obtain

$$
\left|x_{m}(t)\right|^{2}+C_{1} \int_{0}^{t}\left\|x_{m}(\tau)\right\|_{\mathfrak{B}}^{2 k+2} d \tau \leq C_{2} \int_{0}^{T}\|y(\tau)\|_{\mathfrak{B}^{*}}^{\frac{2 k+2}{2 k+1}} d \tau+\left|u_{m}\right|^{2}, C_{i}=\text { const }>0, i=1,2 .
$$


Reflexivity of the space $L_{2 k+2}(0, T ; \mathfrak{B})$ provides the existence of weak limits

$$
\begin{gathered}
x_{m} \rightarrow \hat{x} \text { *-weakly in } L_{\infty}(0, T ; \operatorname{coim} L) ; \\
x_{m} \rightarrow \hat{x} \text { weakly in } L_{2 k+2}(0, T ; \mathfrak{B}) .
\end{gathered}
$$

Since the operator $M$ is $(2 k+2)$-coercive, we get

$$
\int_{0}^{T}\left\langle M\left(x_{m}\right), x_{m}\right\rangle d \tau \leq \int_{0}^{T}\left\|M\left(x_{m}\right)\right\|_{\mathfrak{B}^{*}}\left\|x_{m}\right\|_{\mathfrak{B}} d \tau \leq C^{M} \int_{0}^{T}\left\|x_{m}\right\|_{\mathfrak{B}}^{2 k+1}\left\|x_{m}\right\|_{\mathfrak{B}} d \tau
$$

therefore, $M\left(x_{m}\right)$ are limited in $L_{\frac{2 k+2}{2 k+1}}\left(0, T ; \mathfrak{B}^{*}\right)$. Since the space $L_{\frac{2 k+2}{2 k+1}}\left(0, T ; \mathfrak{B}^{*}\right)$ is reflexive,

$$
M\left(x_{m}\right) \rightarrow \mu \text { is weak in } L_{\frac{2 k+2}{2 k+1}}\left(0, T ; \mathfrak{B}^{*}\right) .
$$

Due to the compact embedding $\mathfrak{N} \hookrightarrow \mathcal{H}$, the sequence $M\left(x_{m}\right) \rightarrow \mu$ in the space $L_{2}(0, T ; \mathcal{H})$. Then by the uniqueness of the limit we get

$$
\mu=M(\hat{x}) .
$$

Turn to the limit in the state equation (14) and condition (15). We get

$$
L \frac{d \hat{x}}{d t}+M(\hat{x})=y, \quad L(\hat{x}(0)-\hat{u})=0 .
$$

Therefore, $\hat{x}=\hat{x}(\hat{u})$ and $\liminf J\left(u_{m}\right) \geq J(\hat{u})$. Consequently, $\hat{u}$ is the start control for the problem $(1)-(3),(6)$.

Further, we consider the operator $M$ as a sum of the operators $M_{1}$ and $M_{2}$, where

$$
\begin{gathered}
<M_{1} x, \zeta>=\alpha_{0} \int_{\Omega} x \zeta d s, \quad x, \zeta \in \mathfrak{B}, \\
<M_{2}(x), \zeta>=\int_{\Omega}\left(\alpha_{1} x^{3} \zeta+\alpha_{2} x^{5} \zeta+\ldots+\alpha_{k-1} x^{2 k-1} \zeta+\alpha_{k} x^{2 k+1} \zeta\right) d s, \quad x, \zeta \in \mathfrak{B} .
\end{gathered}
$$

In order to linearize the equation (11), we need to introduce and to find an additional vector-function $v(s, t)=x(s, t)$. To this end, we define $x=x(s, t)$ as the solution to the linear problem with respect to the vector-function $x$

$$
\begin{gathered}
L \dot{x}+M_{1} x+M_{2}(v)=y, \\
L(x(0)-u(s))=0 .
\end{gathered}
$$

Theorem 3. Let $k=1$ for $n=4$ or $k=1,2$ for $n=3$ or $k \in \mathbb{N}$ for $n=1,2$ and $\lambda \leq \lambda_{1}$,

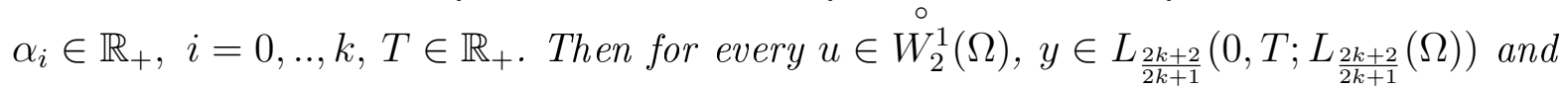
$v \in L_{2 k+2}\left(0, T, L_{2 k+2}(\Omega)\right)$ there exists a weak generalized solution to the problem (16), (17).

Proof. The proof is analogous to the proof of Theorem 1, if we set

$$
\tilde{y}=y-M_{2}(v) \in L_{\frac{2 k+2}{2 k+1}}\left(0, T ; L_{\frac{2 k+2}{2 k+1}}(\Omega)\right) .
$$


The problem of start control and final observation (4) - (6) is equivalent to the problem

$$
\begin{gathered}
L \dot{x}+M_{1} x+M_{2}(v)=y, \quad x(u, v)=v, \\
L(x(0)-u(s))=0, \quad u \in \mathfrak{U}_{a d}, \\
J_{\theta}(x(T), v(T), u)=\theta \cdot \vartheta\left\|x(T)-x_{f}\right\|_{\mathfrak{B}}^{2 k+2}+ \\
+(1-\theta) \cdot \vartheta\left\|v(T)-x_{f}\right\|_{\mathfrak{B}}^{2 k+2}+(1-\vartheta)\|u\|_{\mathfrak{N}}^{2} \rightarrow \inf , \quad \theta, \vartheta \in(0,1) .
\end{gathered}
$$

Definition 5. A triple $(\hat{x}(T), \hat{v}(T), \hat{u}) \in \mathfrak{N} \times \mathfrak{N} \times \mathfrak{U}_{a d}$ is called a solution to the problem of start control and final observation (18) - (20), if

$$
J_{\theta}(\hat{x}(T), \hat{v}(T), \hat{u})=\inf _{(x(T), v(T), u)} J_{\theta}(x(T), v(T), u),
$$

where the triple $(x, v, u) \in \mathfrak{X} \times \mathfrak{X} \times \mathfrak{U}_{a d}$ satisfies (18), (19) in the weak generalized sense. The vector-valued function $\hat{u}$ is called the start control of the problem (18) - (20).

Theorem 4. Let $k=1$ for $n=4$ or $k=1,2$ for $n=3$ or $k \in \mathbb{N}$ for $n=1,2$ and $\lambda \leq \lambda_{1}$, $\alpha_{i} \in \mathbb{R}_{+}, i=0, . ., k, T \in \mathbb{R}_{+}$. Then for every $y \in L_{\frac{2 k+2}{2 k+1}}\left(0, T, \mathfrak{B}^{*}\right)$ there exists a solution to the problem $(18)-(20)$.

Proof. Let $\left\{u_{m}\right\} \in \mathfrak{U}$ be a minimizing sequence, then (20) provides that

$$
\left\|u_{m}\right\|_{\mathfrak{N}}^{2} \leq \text { const, } \forall m \in \mathbb{N} \text {. }
$$

Let us express the weakly convergent sequence $u_{m} \rightarrow \hat{u}$ in $\mathfrak{N}$. According to the Mazur theorem, $\hat{u} \in \mathfrak{U}_{a d}$. Let $x_{m}=x\left(u_{m}\right)$ be a weakly generalized solution of the equation

$$
\begin{gathered}
L \dot{x}_{m}+M_{1} x_{m}+M_{2}\left(v_{m}\right)=y, \quad x_{m}=v_{m}, \\
L\left(x_{m}(0)-u_{m}\right)=0 .
\end{gathered}
$$

Because of the reasoning of Theorem 2

$$
\begin{gathered}
M_{1} x_{m} \in L_{2}\left(0, T ; \mathfrak{N}^{*}\right) \\
M_{2}\left(v_{m}\right) \in L_{\frac{2 k+2}{2 k+1}}\left(0, T ; \mathfrak{B}^{*}\right) .
\end{gathered}
$$

It follows from $(21)$ that $\dot{x}_{m} \in L_{2}(0, T$; coim $L) \cap L_{2 k+2}(0, T ; \mathfrak{B})$. We can express the subsequence denoted by $\left\{x_{m}\right\},\left\{v_{m}\right\},\left\{u_{m}\right\}$ :

$$
\begin{gathered}
x_{m} \rightarrow \hat{x} * \text {-weakly in } L_{\infty}(0, T ; \operatorname{coim} L), \\
v_{m} \rightarrow \hat{v} * \text {-weakly in } L_{\infty}(0, T ; \operatorname{coim} L), \\
\frac{d}{d t} L x^{m} \rightarrow \frac{d}{d t} L \hat{x} \text { weakly in } L_{2}(0, T ; \operatorname{im} L), \\
M_{1} x_{m} \rightarrow M_{1} \hat{x} \text { weakly in } L_{2}\left(0, T ; \mathfrak{N}^{*}\right), \\
M_{2}\left(v_{m}\right) \rightarrow \omega \text { weakly in } L_{\frac{2 k+2}{2 k+1}}\left(0, T ; \mathfrak{B}^{*}\right),
\end{gathered}
$$


By anology with the proof of Theorem 1, we obtain $\omega=M_{2}(\hat{v})$. Turn to the limit in the state equation (21), (22). Therefore, we get

$$
\begin{aligned}
L \dot{\hat{x}}+M_{1} \hat{x}+M_{2}(\hat{v}) & =y, \quad \hat{x}=\hat{v} \\
L(\hat{x}(0)-\hat{u}) & =0 .
\end{aligned}
$$

Therefore, $\hat{x}=\hat{x}(\hat{v}, \hat{u})$ and $\liminf J\left(u_{m}, v_{m}\right) \geq J(\hat{u}, \hat{v})$. Consequently, $(\hat{x}(T), \hat{v}(T), \hat{u})$ is the solution to the problem $(18)-(20)$.

\section{Algorithm of the Numerical Method to Find the Start Control and Final Observation for the Model of an I-Beam Deformation}

Based on the theoretical results obtained in the previous paragraphs, we develop an algorithm to find the approximate solution to the problem of start control and final observation for the mathematical model of an I-beam deformation on the basis of the modified decomposition method, the Galerkin method and the Ritz method. Let $\sigma$ be a spectrum of the operator $(-\Delta)$ with the homogeneous Dirichlet condition, and $\left\{\lambda_{k}\right\}$ be a set of the eigenvalues numbered in non-decreasing order and $\left\{\varphi_{k}\right\}$ be a family of the corresponding eigenfunctions, which are orthonormalized relatively to the scalar product $<\cdot, \cdot>$ in $L_{2}(\Omega)$. Using the Galerkin method, we search for the approximate solution in the form

$$
\tilde{x}(s, t)=x_{m}(s, t)=\sum_{k=1}^{m} a_{k}(t) \varphi_{k}(s),
$$

where $m \in \mathbb{N}$. In order to take into account the effects of the degenerate equation, it is necessary to take $m$ such that $m>l$, where $l=\operatorname{dim} \operatorname{ker}(-\lambda-\Delta)$. Represent the right side of the equation (1) as

$$
\tilde{y}(s, t)=\sum_{k=1}^{m} y_{k}(t) \varphi_{k}(s) .
$$

Also, present the initial function $u(s)$ in the form

$$
\tilde{u}=\sum_{k=1}^{m} u_{k} \varphi_{k}(s)
$$

Decompose the equation (1) (for $k=1$ ). In the equation (1), introduce an unknown function $v(s, t)$ such that

$$
\begin{gathered}
(-\lambda-\Delta) x_{t}+\alpha_{0} x+\alpha_{1} v^{3}=y, \\
x(s, t)=v(s, t) .
\end{gathered}
$$

Because of the equality (27) the quality functionality (4) is equivalent to the functional

$$
\begin{aligned}
& J(x, u)=J_{\theta}(x, u, v)=\theta \cdot \beta\left\|x(T)-x_{f}\right\|_{L_{4}(\Omega)}^{4}+ \\
& \quad+(1-\theta) \cdot \beta\left\|v(T)-x_{f}\right\|_{L_{4}(\Omega)}^{4}+(1-\beta) \cdot\|u\|_{W_{2}^{1}(\Omega)}^{2}, \quad \beta, \theta \in(0,1) .
\end{aligned}
$$


Further, we search for an approximate solution to the control problem (1) - (3), (6) using the penalty method described in [11]. Consider the equivalent control problem, where the formula (28) for the approximate solution is achieved by introducing a new functional in the form

$$
\begin{aligned}
J(x, u)=J_{\theta}(x, u, v)=\theta \cdot \beta \| x(T)-x_{f} & \left\|_{L_{4}(\Omega)}^{2}+(1-\theta) \cdot \beta\right\| v(T)-x_{f} \|_{L_{4}(\Omega)}^{4}+ \\
& +(1-\beta) \cdot\|u\|_{W_{2}^{1}(\Omega)}^{2}+r_{\varepsilon}\|x-v\|_{L_{4}\left(0, T ; L_{4}(\Omega)\right)}^{4},
\end{aligned}
$$

where the penalty parameter $r_{\varepsilon} \rightarrow+\infty$ for $\varepsilon \rightarrow 0+$.

Represent $\tilde{v}(s, t)$ in the form of the sum

$$
\tilde{v}(s, t)=\tilde{v}_{m}(s, t)=\sum_{k=1}^{m} v_{k}(t) \varphi_{k}(s) .
$$

According to the Ritz method, we search for $v_{k}(t), k=1, . ., m$, in the form

$$
v_{k}(t)=v_{k}(t, N)=\sum_{j=0}^{N} b_{j} t^{n},
$$

under the condition that $v_{k}(0, N)=x_{k}(0)=u_{k}, \quad k=1, . ., m$. Substitute $(23)-(25),(30)$ in the equation (26) and multiply the resulting equation on the eigenfunctions $\varphi_{k}(s), k=$ $1, . ., m$ scalarly in $L_{2}(\Omega)$. We obtain the system of equations

$$
<(-\lambda-\Delta) \tilde{x}_{t}, \varphi_{k}>+<\alpha_{0} \tilde{x}, \varphi_{k}>+<\alpha_{1} \tilde{v}^{3}, \varphi_{k}>=<\tilde{y}, \varphi_{k}>
$$

with the Showalter - Sidorov conditions

$$
<(-\lambda-\Delta)(x(s, 0)-u), \varphi_{k}>=0 .
$$

Solve the problem $(32),(33)$ relatively the unknown $a_{k}(t)$. Note that depending on parameter $\lambda$, equations in the system can be either differential or algebraic. Consider these cases in more detailes:

- If $\lambda \notin \sigma$, then all equations of the system (32) is ordinary differential equations of the first order. In order to solve this system relatively $a_{k}(t), k=1, \ldots, m$, we find $m$ initial conditions $a_{k}(0)=u_{k}, \quad k=1, . ., m$, from the initial conditions (33). Further, we solve the obtained system of the linear differential equations of the first order with the initial conditions, and express unknown coefficients $a_{k}(t)$ of the approximate solution $\tilde{x}(s, t)$ by $v_{k}(t), u_{k}, k=1, . ., m$.

- If $\lambda \in \sigma$, then the first equation is algebraic, and the rest ones are differential. Separately, consider the system of differential equations having first order and the algebraic equation. Using the Showalter - Sidorov conditions, we find $(m-1)$ initial conditions. Solve the system of the algebraic and differential equations, and express the unknown coefficients $a_{k}(t), k=2, . ., m$ of the approximate solution $\tilde{x}(s, t)$ by $v_{k}(t)$, and $u_{k}, k=1, . ., m$. From the algebraic equation we find $a_{1}(t)$ and $u_{1}=a_{1}(0)$. Turn to search for the minimum of functional. Substitute the obtained decompositions in the functional. 
We select coefficients $b_{j}$ such that the functions $v_{k}(t, N)$ and $u_{k}$ give the minimum of the functional (29). Therefore, the problem is reduced to search for an extremum for function of several variables.

Example 1. The problem is to find an approximate solution to the problem of start control and final observation of the problem (2), (3), (6), (28) for

$$
\begin{gathered}
\lambda=-2, \quad \alpha_{0}=5, \alpha_{1}=4, \\
\Omega=(0, \pi), T=\frac{2}{5}, \theta=\frac{21}{55}, \beta=\frac{999}{1000}, \varepsilon=\frac{1}{200}, m=2, N=3, \\
x_{d}=\frac{\sqrt{2}}{3 \sqrt{\pi}} \sin (s), \quad y=0 .
\end{gathered}
$$

On the basis of the developed numerical method to find the start control and final observation, we turn to an equivalent problem of the start control and final observation:

$$
\begin{gathered}
J(x(T), v(T), u)=\frac{21}{55} \cdot \frac{999}{1000} \int_{0}^{\pi}\left|x(s, T)-\frac{\sqrt{2}}{3 \sqrt{\pi}} \sin s\right|^{4} d s+ \\
+\left(1-\frac{21}{55}\right) \cdot \frac{999}{1000} \int_{0}^{\pi}\left|v(s, T)-\frac{\sqrt{2}}{3 \sqrt{\pi}} \sin s\right|^{4} d s+ \\
+\left(1-\frac{999}{1000}\right) \int_{0}^{\pi}\left[|u(s)|^{2}+\left|u^{\prime}(s)\right|^{2}\right] d s+200 \int_{0}^{\pi} \int_{0}^{T}|x(s, t)-v(s, t)|^{4} d s d t \rightarrow \inf
\end{gathered}
$$

solutions by the solutions to the Showalter - Sidorov - Dirichlet problem (2), (3) for the equation

$$
2 x_{t}^{\prime}-x_{t s s}^{\prime \prime \prime}+5 x+4 v^{3}=0 .
$$

Consider the Sturm - Liouville problem

$$
-X^{\prime \prime}(x)=\lambda X(x), \quad X(0)=X(\pi)=0 .
$$

The eigenfunctions and eigenvalues of the problem (32) have the form:

$$
\varphi_{k}(s)=\sqrt{\frac{2}{\pi}} \sin k s, \lambda_{k}=k^{2}, k=1,2, \ldots
$$

On the basis of the Galerkin projective method, the approximate solution $\tilde{x}(s, t), \tilde{v}(s, t), \tilde{u}(s)$ to the problem is represented as

$$
\tilde{x}(s, t)=\sum_{k=1}^{m} x_{k}(t) \varphi_{k}(s), \quad \tilde{v}(s, t)=\sum_{k=1}^{m} v_{k}(t) \varphi_{k}(s), \quad \tilde{u}(s)=\sum_{k=1}^{m} u_{k} \varphi_{k}(s) .
$$

The results of the program "Numerical study of the problem of start control and final observation for the model of an I-beam deformation" calculations are control coefficients such that the value of the functional $J=0.00000285$. Graphs of approximate solution to the problem (2), (3), (6), (28) are shown in Fig. 1. 


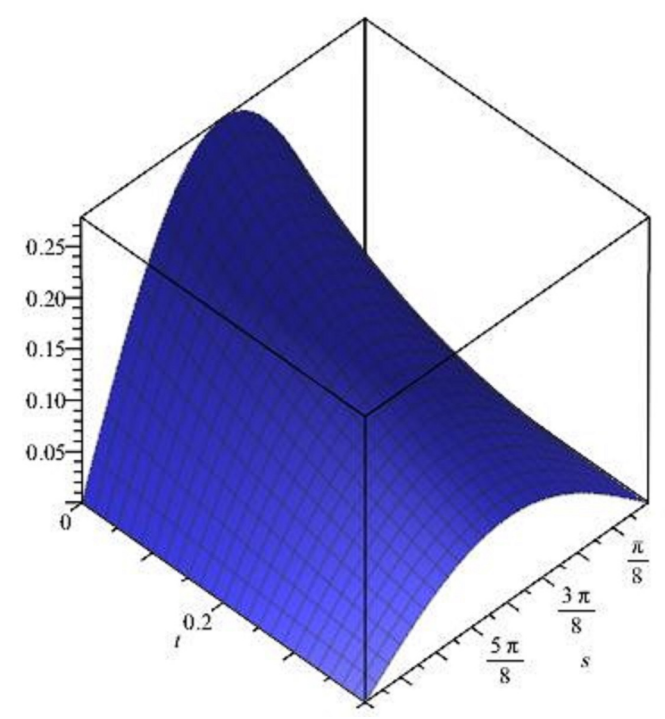

a) funtion $\tilde{x}(s, t)$

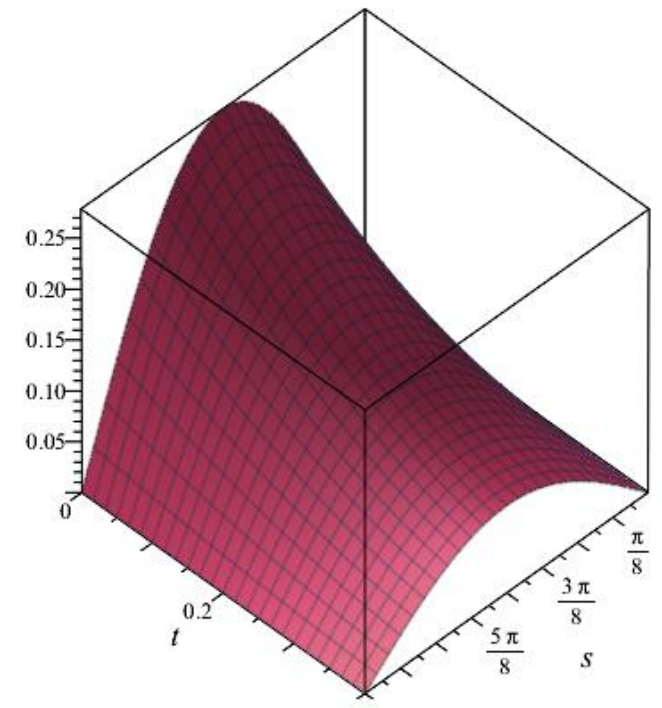

b) funtion $\tilde{v}(s, t)$

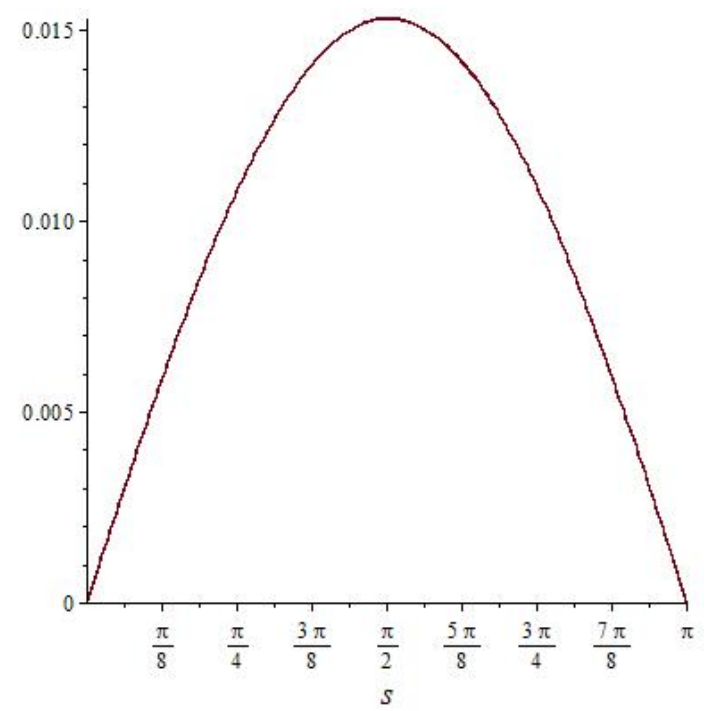

c) funtion $\tilde{u}(s)$

Fig. 1. The approximate solution $\tilde{x}(s, t), \tilde{v}(s, t), \tilde{u}(s)$ to the problem $(2),(3),(6),(26)$

In order to compare the obtained functions $\tilde{x}(s, t), \tilde{v}(s, t)$ and the required state $x_{d}(s)$, we construct the graph of these functions at the moment $t=\frac{2}{5}$ (see Fig. 2). The difference between the required functions $\tilde{x}(s, t)$ and $\tilde{v}(s, t)$ is small:

$$
\Delta=\left(\int_{0}^{T}\left(\int_{0}^{\pi}|\tilde{x}(s, t)-\tilde{v}(s, t)|^{4} d s\right) d t\right)^{\frac{1}{4}}=0.0000012365046 .
$$




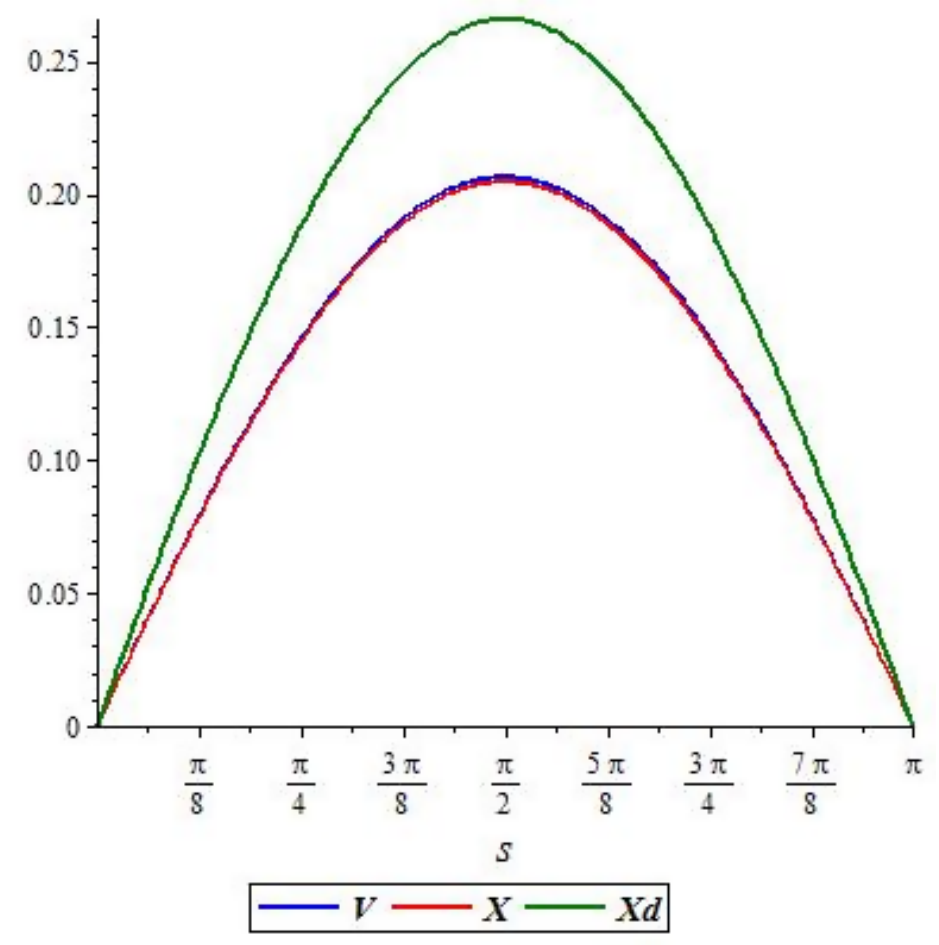

Fig. 2. Function $\tilde{x}\left(s, \frac{2}{5}\right), \tilde{v}\left(s, \frac{2}{5}\right), x_{d}(s), s \in(0, \pi)$

\section{References}

1. Hoff N.J. Creep Buckling. Journal of the Aeronautical Sciences, 1956, no. 7, pp. 1-20.

2. Sviridyuk G.A., Kazak V.O. The Phase Space of an Initial-Boundary Value Problem for the Hoff Equation. Mathematical Notes, 2002, vol. 71, no. 2, pp. 262-266. doi: 10.1023/A:1013919500605

3. Bayazitova A.A. The Showalter - Sidorov Problem for the Hoff Model on a Geometric Graph. The Bulletin of Irkutsk State University. Series: Mathematics, 2011, vol. 4, no. 1, pp. 2-8. (in Russian)

4. Sviridyuk G.A., Shemetova V.V. Hoff Equations on Graphs. Differential Equations, 2006, vol. 42, no. 1, pp. 139-145. doi: 10.1134/S0012266106010125

5. Sviridyuk G.A., Manakova N.A. An Optimal Control Problem for the Hoff Equation. Journal of Applied and Industrial Mathematics, 2007, vol. 1, no. 2, pp. 247-253. doi: 10.1134/S1990478907020147

6. Shafranov D.E., Shvedchikova A.I. The Hoff Equation as a Model of Elastic Shell. Bulletin of the South Ural State University. Series: Mathematical Modelling, Programming and Computer Software, 2012, no. 18 (277), issue 12, pp. 77-81. (in Russian)

7. Lions J.-L. Controle optimal de systemes gouvernes par des equations aux daerivaees partielles. Paris, Dunod, 1968. 
8. Sviridyuk G.A., Efremov A.A. Optimal Control of Sobolev Type Linear Equations with Relativity p-Sectorial Operators. Differential Equations, 1995, vol. 31, no. 11, pp. 1882-1890.

9. Zamyshlyaeva A.A., Tsyplenkova O.N. Optimal Control of Solutions of the Showalter Sidorov - Dirichlet Problem for the Boussinesq - Love Equation. Differential Equations, 2013, vol. 49, no. 11, pp. 1356-1365. doi: 10.1134/S0012266113110049

10. Keller A.V., Sagadeeva M.A. The Optimal Measurement Problem for the Measurement Transducer Model with a Deterministic Multiplicative Effect and Inertia. Bulletin of the South Ural State University. Series: Mathematical Modelling, Programming and Computer Software, 2014, vol. 7, no. 1, pp. 134-138. doi: 10.14529/mmp140111 (in Russian)

11. Manakova N.A. Method of Decomposition in the Optimal Control Problem for Semilinear Sobolev Type Models. Bulletin of the South Ural State University. Series: Mathematical Modelling, Programming and Computer Software, 2015, vol. 8, no. 2, pp. 133-137. doi: 10.14529/mmp150212 (in Russian)

12. Bogatyreva E.A. The Start Control and Final Observation Problem for a QuasiLinear Sobolev Type Equation. Bulletin of the South Ural State University. Series: Mathematics. Mechanics. Physics, 2015, vol. 7, no. 4, pp. 5-10. doi: 10.14529/mmph150401 (in Russian)

13. Gajewski H., Groger K., Zacharias K. Nichtlineare Operatorgleichungen und Operatordfferentialgleichungen. Berlin, Akademie Verlag, 1974.

14. Al'shin A.B., Korpusov M.O., Sveshnikov A.G. Blow-up in Nonlinear Sobolev Type Equations. Series in Nonlinear Analisys and Applications, 15, De Gruyter, 2011. doi: $10.1515 / 9783110255294$

15. Lyons J.-L. Quelques methodes de raesolution des problemes aux limites nonlineaires. Paris, Dunod, 1969.

16. Manakova N.A. Mathematical Models and Optimal Control of the Filtration and Deformation Processes. Bulletin of the South Ural State University. Series: Mathematical Modelling, Programming and Computer Software, 2015, vol. 8, no. 3, pp. 5-24. doi: 10.14529/mmp150301 (in Russian)

Natalia A. Manakova, DSc (Math), Professor, Department of Equation of Mathematical Physics, South Ural State University (Chelyabinsk, Russian Federation), manakovana@susu.ru.

Ksenia V. Vasiuchkova, Graduate Student, Department of Equation of Mathematical Physics, South Ural State University (Chelyabinsk, Russian Federation), vasiuchkovakv@susu.ru.

Received June 7, 2017 


\title{
ЧИСЛЕННОЕ МОДЕЛИРОВАНИЕ СТАРТОВОГО УПРАВЛЕНИЯ И ФИНАЛЬНОГО НАБЛЮДЕНИЯ В МОДЕЛИ ДЕФОРМАЦИИ ДВУТАВРОВОЙ БАЛКИ
}

\author{
Н.А. Манакова, К.В. Васючкова
}

\begin{abstract}
Статья посвящена изучению стартового управления и финального наблюдения решеними задачи Шоуолтера - Сидорова для математической модели деформации двутавровой балки. Строятся достаточные условия существования стартового управления и финального наблюдения слабыми обобщенными решениями исследуемой модели с начальным условием Шоуолтера - Сидорова. На основе теоретических результатов построен алгоритм численного метода нахождения приближенного решения задачи стартового управления и финального наблюдения исследуемой задачи. Приводятся вычислительные эксперименты.

Ключевые слова: уравнения соболевского типа; задача стартового управления $и$ финального наблюдения; модель деформации двутавровой балки; проекционный метод Галеркина; метод декомпозиции.
\end{abstract}

\section{Литература}

1. Hoff, N.J. Creep Buckling / N.J. Hoff // Journal of the Aeronautical Sciences. - 1956. № $7 .-$ P. 1-20.

2. Свиридюк, Г.А. Фазовое пространство начально-краевой задачи для уравнения Хоффа / Г.А. Свиридюк, В.О. Казак // Математические заметки. - 2002. - Т. 71, № 2. - C. 292-297.

3. Баязитова, А.А. Задача Шоуолтера - Сидорова для модели Хоффа на геометрическом графе / А.А. Баязитова // Известия Иркутского государственного университета. Серия: Математика. - 2011. - Т. 4, № 1. - С. 2-8.

4. Свиридюк, Г.А. Уравнения Хоффа на графе / Г.А. Свиридюк, В.В. Шеметова // Дифференциальные уравнения. - 2006. - Т. 42, № 1. - С. 126-131.

5. Свиридюк, Г.А. Задача оптимального управления для уравнения Хоффа / Г.А. Свиридюк, Н.А. Манакова // Сибирский журнал индустриальной математики. - 2005. - Т. 8, № 2. - С. 144-151.

6. Шафранов, Д.Е. Уравнение Хоффа как модель упругой оболочки / Д.Е. Шафранов, А.И. Шведчикова // Вестник ЮУрГУ. Серия: Математическое моделирование и программирование. - 2012. - № 18 (277), вып. 12. - С. 77-81.

7. Лионс, Ж.-Л. Управление сингулярными распределенными системами Ж.-Л. Лионс. - М.: Наука, 1987.

8. Свиридюк, Г.А. Задача оптимального управления для одного класса уравнений типа Соболева / Г.А. Свиридюк, А.А. Ефремов // Известия вузов. Математика. 1996. - № 2. - C. 75-83. 
9. Замышляева, А.А. Оптимальное управление решениями начально-конечной задачи для уравнения Буссинеска - Лява /А.А. Замышляева, О.Н. Цыпленкова // Вестник ЮУрГУ. Серия: Математическое моделирование и программирование. 2012. - № 5 (264), вып. 11. - С. 13-24.

10. Келлер, А.В. Задача оптимального измерения для модели измерительного устройства с детерминированным мультипликативным воздействием и инерционностью / А.В. Келлер, М.А. Сагадеева // Вестник ЮУрГУ. Серия: Математическое моделирование и программирование. - 2014. - Т. 7, № 1. - С. 134-138.

11. Манакова, Н.А. Метод декомпозиции в задаче оптимального управления для полулинейных моделей соболевского типа / Н.А. Манакова // Вестник ЮУрГУ. Серия: Математическое моделирование и программирование. - 2015. - Т. 8, № 2. C. $133-137$.

12. Богатырева, Е.А. Задача стартового управления и финального наблюдения для одного квазилинейного уравнения соболевского типа / Е.А. Богатырева // Вестник ЮУрГУ. Серия: Математика. Механика. Физика. - 2015. - Т. 7, № 4. - С. 5-10.

13. Гаевский, Х. Нелинейные операторные уравнения и операторные дифференциальные уравнения / Х. Гаевский, К. Грегер, К. Захариас. - М.: Мир, 1978.

14. Al'shin, A.B. Blow-up in Nonlinear Sobolev Type Equations / A.B. Al'shin, M.O. Korpusov, A.G. Sveshnikov. - De Gruyter, 2011.

15. Лионс, Ж.-Л. Некоторые методы решения нелинейных краевых задач / Ж.-Л. Лионс. - М.: Мир, 1972.

16. Манакова, Н.А. Математические модели и оптимальное управление процессами фильтрации и деформации / Н.А. Манакова // Вестник ЮУрГУ. Серия: Математическое моделирование и программирование. - 2015. - Т. 8, № 3. - С. 5-24.

Манакова Наталья Александровна, доктор физико-математических наук, профессор, кафедра уравнений математической физики, Южн-Уральский государственный университет (е. Челябинск, Российская Федераиия), manakovana@susu.ru.

Васючкова Ксения Владимировна, магистрант, кафедра уравнений математической физики, Южно-Уральский государственный университет (г. Челябинск, Российская Федерачия), vasiuchkovakv@susu.ru.

Поступила в редакцию 7 июня 2017 г. 